\title{
Evaluating the Readiness of Management Schools to Execute Knowledge Management
}

\author{
Gholamreza Jandaghi ${ }^{1, *}$, Hamid Reza Irani ${ }^{1}$, Ehssan Jandaghi ${ }^{2}$, \\ Zeinab Sadat Mousavi ${ }^{1}$, Maryam Davoodavabi ${ }^{1}$ \\ ${ }^{1}$ Faculty of Management and Accountancy, Farabi Campus, University of Tehran, Iran \\ ${ }^{2}$ Iran University of Science and Technology, Tehran, Iran \\ *E-mail address: jandaghi@ut.ac.ir
}

\begin{abstract}
A new branch of management called knowledge management is created for improved application of knowledge capital in organizations. Applying such process improves knowledge processes and enhances organizational knowledge by linking knowledge management with organizational strategies. Also, it provides proper guidelines to compensate current deficiencies and helps organization to keep its competitive advantage. In present study and after brief study of knowledge management concepts by identifying and considering affecting factors on management success and knowledge management enablers, research hypotheses were revealed to evaluate organizational readiness to execute knowledge management in both individual and organizational sections. The readiness of Management Schools in Qom province of Iran to execute knowledge management was assessed and confirmed by a questionnaire and the relevant scores were computed. Then, the weak points were identified according to the readiness of the statistical population and proper guidelines were provided to remove deficiencies.
\end{abstract}

Keywords: Knowledge management; faculty members; Students; staff; readiness

\section{INTRODUCTION}

Organizations are not excluded and have experienced paramount changes. To achieve a competitive advantage, survive and treat with spatial changing conditions, organizations have recourse to use new managerial tools, techniques and principles in the age of rapid and increasingly transformations (Noruzian, 2007). Nowadays, the driving force of organizational growth of firms does not limit to human force and capital. The most important variable of overall growth of organizations and economic firms is knowledge. In its real meaning, knowledge is a set of human skills and capabilities accompanied with awareness of better production techniques. It is too common in present and future organizations to apply such perception of knowledge. In this way, organizations should try to use their own and environmental knowledge properly and on-time. Such approach has developed a new concept called knowledge management (Amin Moghadam \& Sotudeh Riazi, 2007).

Knowledge management is considered by many authors as a key strategy to achieve organizational success and survival in today hyper competition and unpredictable ambience. People can achieve a new thinking pattern by which they can redefine the affairs and the 
styles to perform them if they can learn and use knowledge in organizations creatively. Therefore, knowledge management should have learning perspectives and tools. A well established knowledge management system can provide organizations and even individuals with sustainable profitability (Hamidizadeh, 2008).

\section{KNOWLEDGE MANAGEMENT DEFINITION}

Hidden complexity in knowledge management definition is, in part, due to the existing challenges in knowledge definition. There are varied definitions on knowledge management in textbooks some of which are mentioned below:

Robbins defines knowledge management as a process to prepare and disseminate organizational information in manner right people can achieve right information in right time (Robbins cited by Ray, 2008). Armstrong defines knowledge management a process or performance to create, acquire, share and apply knowledge which leads into learning increase and performance improvement (Armstrong, 2010: 22). Davenport and Prusak define knowledge management as the usage and development of knowledge assets of an organization to achieve its goals. A managed knowledge includes both explicit and implicit knowledge. Managing such knowledge involves ass processes related to identifying, sharing and generating knowledge. It requires a system to generate and keep knowledge stockpiles as well as knowledge dissemination and organizational learning. Successful organizations in knowledge management consider it as an organizational capital and develop organizational values and rules to procure knowledge generation and sharing (Davenport and Prusak, 1998).

Nonaka believes that knowledge management is a process by which organization generates wealth or intellectual capital (Nonaka, 1994).

\section{KNOWLEDGE MANAGEMENT ENABLERS}

Knowledge management enablers in an organization encourage knowledge development, knowledge generation inside the organization as well as sharing and protecting it (Yeh et al, 2006). In fact, knowledge enabler is the capability of an organization to expand its own knowledge by which it protects its organizational knowledge and encourages knowledge generation culture as well as knowledge sharing among organizational members. Executing and using knowledge management would be easier and simpler if such vital enablers exist in the organization and, consequentially, organizations are able to use their resources more efficiently and effectively (Gaffoor, 2008; Yeh et al, 2000).

There is an increase in the number of knowledge management enabler models and organizational readiness to execute knowledge management in recent years. Today, each organization measures its readiness to execute or implement transformation projects in various IT fields in order to prevent capital wasting. To the same reason, paramount models are developed to measure organizational readiness in various fields. Table 1 outlines knowledge management enabler models and organizational readiness to execute knowledge management more relevant to present study. 


\section{RESEARCH METHODOLOGY}

Research statistical population consists of all academic members, staff and student in Management schools of Qom province in Iran. There are several universities in Qom province of which 5 universities have management school. These universities are Farabi Campus of University of Tehran, Qom university, Hazrat Masoumeh University, Payam noor university and Islamic Azad university. The sample consists of 520 from the population which has been drawn using random stratified sampling method. We used a 5 point likert questionnaire to gather the required data. The Cronbach Alpha of reliability for the whole questionnaire and its dimensions was at least 0.89 . We distributed 520 questionnaires of which 398 were returned and 390 were used in the analysis. We used descriptive statistics to assess the level of readiness in management schools to execute knowledge management.

\section{THE RESEARCH MODEL}

Based on the extensive literature on knowledge management, we used the research model presented in Figure 1 to develop an appropriate questionnaire for assessing the readiness of KM in management schools.
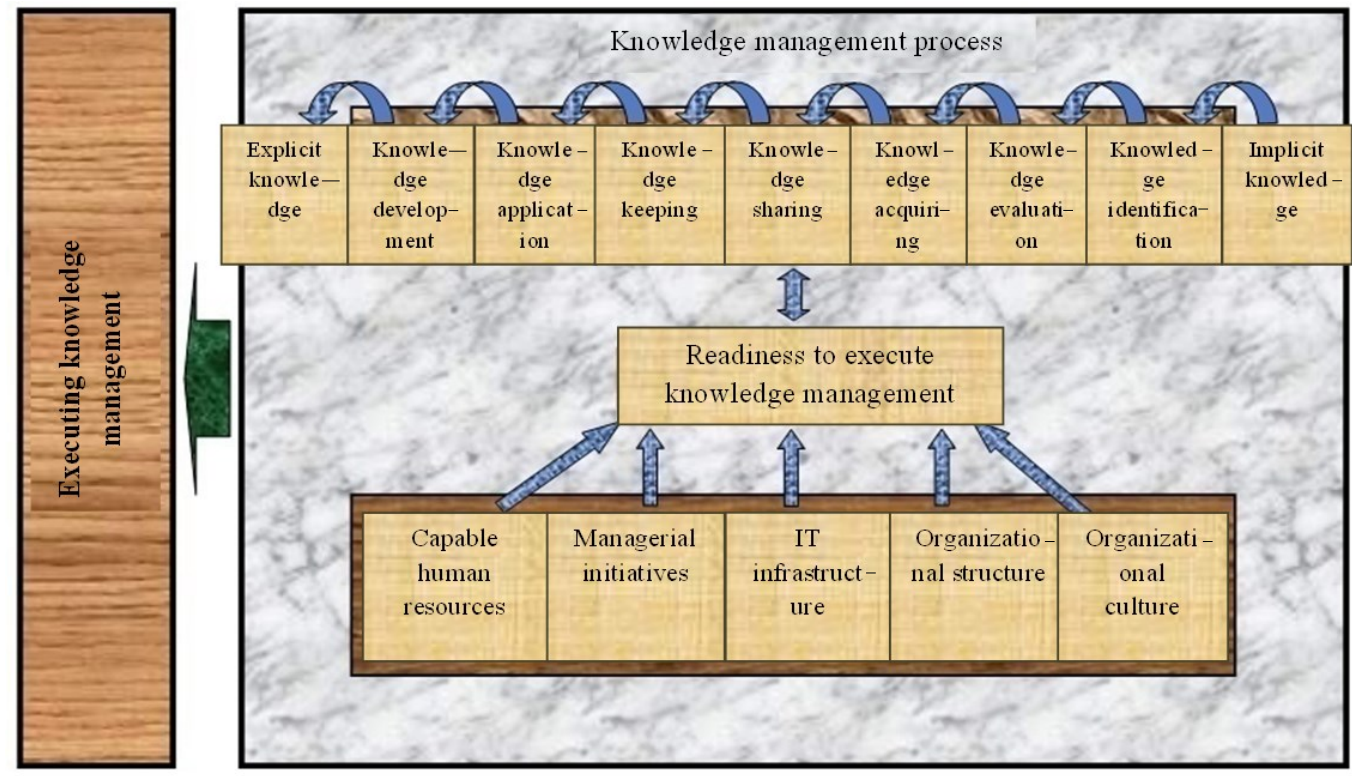

Figure 2. Research model.

After the questionnaire was administered to sample individuals where they completed and returned. Tables 1 shows the level of readiness based on the faculty members, staff and the students' opinion. 
Table 1. Level of readiness to execute knowledge management enablers based on the sample.

\begin{tabular}{|c|c|c|c|c|c|c|c|c|c|c|c|c|}
\hline \multirow{2}{*}{ Readiness } & $\begin{array}{c}\text { Organizational } \\
\text { culture }\end{array}$ & $\begin{array}{c}\text { Organizational } \\
\text { structure }\end{array}$ & \multicolumn{2}{|c|}{$\begin{array}{c}\text { IT } \\
\text { infrastructure }\end{array}$} & \multicolumn{2}{|c|}{$\begin{array}{c}\text { Management } \\
\text { initiatives }\end{array}$} & \multicolumn{2}{|c|}{ HR } & \multicolumn{3}{|c|}{ Total } \\
\cline { 2 - 13 } & Mean & Mode & Mean & Mode & Mean & Mode & Mean & Mode & Mean & Mode & Mean & Mode \\
\hline $\begin{array}{c}\text { Faculty } \\
\text { members }\end{array}$ & 2.74 & 3.00 & 2.69 & 3.00 & 2.99 & 3.00 & 2.48 & 3.00 & 2.95 & 3.00 & 2.78 & 3.00 \\
\hline Staff & 2.36 & 3.00 & 2.39 & 3.00 & 3.13 & 3.00 & 2.20 & 2.00 & 2.90 & 3.00 & 2.60 & 3.00 \\
\hline Students & 2.56 & 3.00 & 2.56 & 3.00 & 2.73 & 3.00 & 2.44 & 3.00 & 2.76 & 3.00 & 2.61 & 3.00 \\
\hline Total & 2.51 & 3.00 & 2.59 & 3.00 & 2.78 & 3.00 & 2.43 & 3.00 & 2.72 & 3.00 & 2.61 & 3.00 \\
\hline
\end{tabular}

As shown in Table 1, the management schools have a relatively good situation in IT infrastructure for knowledge management compared to other four KM enablers.

The overall level of readiness to execute knowledge management in management schools of Qom province is shown in Figure 1. As can be seen, there is a big gap between what is needed and what it is.

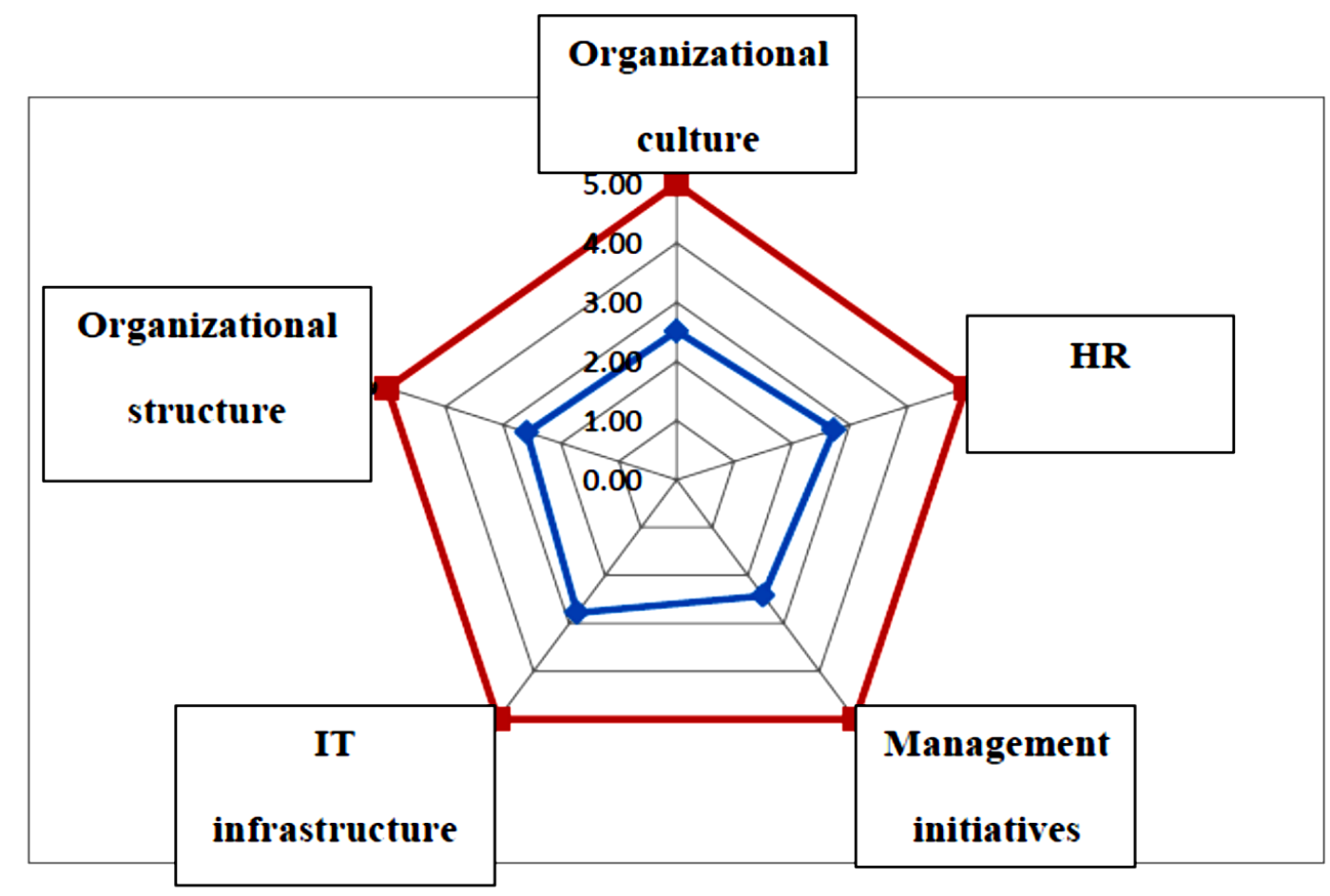

Figure 1. Level of readiness of KM in management schools. 


\section{DISCUSSION, CONCLUSIONS AND RECOMMENDATIONS}

According to computed scores for each factor, it is determined that IT infrastructure with overall score of 2.78 has the necessary readiness to execute knowledge management. Based on the overall readiness of management schools to execute knowledge management, it was determined that this indicator is more regarded at mentioned organization. In next priorities, the scores of indicators were empowerment with overall score of 2.72, organizational structure with score of 2.59, organizational culture with score of 2.51 and finally managerial initiatives with score of 2.43 respectively. The final result of analysis is that:

\section{"Management schools lack the necessary readiness to execute knowledge management."}

In order to execute knowledge management in these schools, one should initially raise the affecting factors on successful implementation of knowledge management to a plausible readiness and then organization should be supported in executing knowledge management through adopting proper methods.

\section{ACKNOWLEDGEMENT}

This Research has been done by financial support of University of Tehran, Grant number 9660939/1/01.

\section{References}

[1] Amin Moghadam Ali, Sotudeh Riazi, Maryam (2007). "Proviing a model for knowledge management development in research organization by an approach on effective application of ICT technology", National Conference on knowledge management, Tehran.

[2] Armstrong Micheal (2010). "HR strategic management", translated by Mohammad Arabi and Omid Mahdieh, Tehran, Cultural Researches Office Publications.

[3] Davenport T., Prusak L. (1998), “Working knowledge-How organizations manage what they know", Harvard Business School Press: Boston, MA .

[4] Gaffoor Shamin (2008). "Assessing readiness for the implementation of knowledge management in local government: The case of Stellenbosch Municipality" , These for de degree of Master of Commerce at Stellenbosch University, School of Public Management and Planning, Faculty of Economic and Management Sciences.

[5] Hamidizadeh Mohammad Reza (2008), "Training guidelines to disseminate knowledge management", HR Management in Oil Industry Quarterly, Energy International Studies Institute, vol. 1.

[6] Nonaka I., Organization Science 5(1) (1994) 14-37.

[7] Noruzian, Meysam (2007), "the knowledge of knowledge management", Tadbir Monthly, vol. 176.

[8] Ray Loye, Journal of Knowledge Management 12(3) (2008) 156-168.

[9] Yeh Ying, Jung Lai, Sun Quae Ho, Chin Tsange, Industrial Management \& Data Systems 106(6) (2006) 793-810. 
[10] Mohsen Mehrara, Maysam Musai, International Letters of Social and Humanistic Sciences 5 (2013) 55-62

[11] Rezgar Mohammadi, Ezatullah Naderi, International Letters of Social and Humanistic Sciences 9 (2013) 22-30.

[12] Morteza Ziaee, International Letters of Social and Humanistic Sciences 9 (2014) 57-65.

[13] Sakineh Ghayazi, Faranak Omidian, Mohammed Hosseinpoor, International Letters of Social and Humanistic Sciences 10(1) (2014) 51-61. 